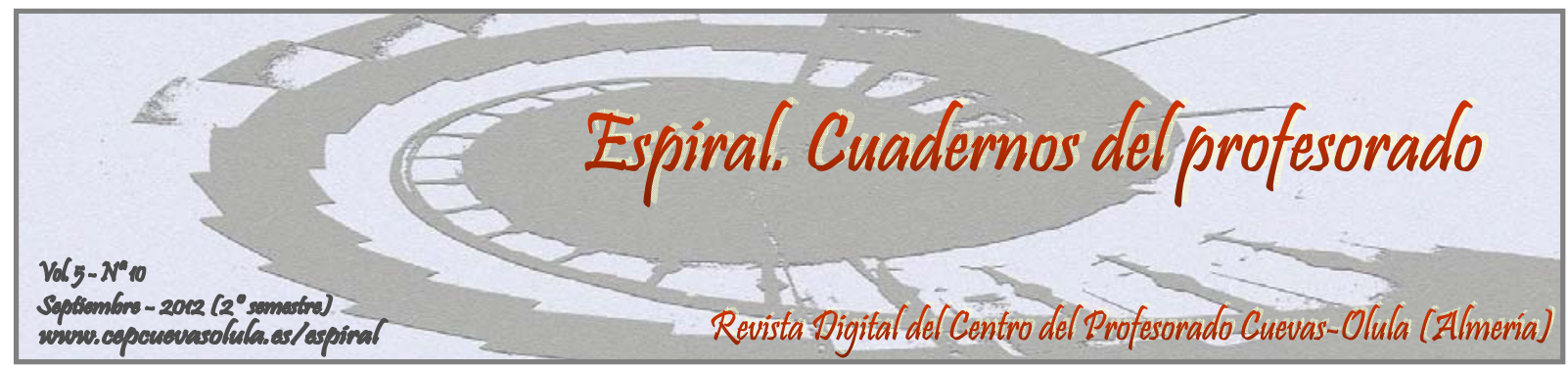

\title{
LA COMUNICACIÓN INTERCULTURAL A TRAVÉS DE LA MÚSICA
}

\author{
INTERCULTURAL COMMUNICATION THROUGH MUSIC \\ María del Mar Bernabé Villodre \\ Departamento de Didáctica de la Expresión Musical, Plástica y Corporal, Universidad de \\ Valencia, Valencia, España
}

RESUMEN: La música tiene la capacidad de transmitir conocimientos, habilidades y valores intrínsecos a la cultura del compositor, y al mismo tiempo transmite emociones y sentimientos comunes a todas las culturas; por ello puede decirse que la música es un instrumento idóneo para el establecimiento de un diálogo intercultural. La acción comunicativa musical siempre ha sido objeto de análisis; aunque ha sido la falta de diálogo cultural la que ha aumentado la consideración de que la música puede posibilitar el camino hacia la adquisición de la Interculturalidad. Este artículo muestra cómo la música favorece el proceso comunicativo intercultural, al considerarse como la principal herramienta de trabajo en contextos educativos culturalmente diversos. Se muestra cómo la música ayuda a construir un sentido de pertenencia y a valorar las producciones propias y ajenas, facilitando la extrapolación a otras actividades de la vida cotidiana. Este artículo contribuye a mostrar cómo se puede considerar que la música, entendida como muestra cultural de cada país, es un producto intrínsecamente intercultural y facilita/favorece el diálogo intercultural, debido a su gran carga de valores y a que lleva consigo la imagen del tiempo y de la sociedad de pertenencia.

Palabras clave: música, comunicación intercultural, interculturalidad, creación musical, comunicación a través de la práctica musical.

ABSTRACT: Music has the ability to transmit knowledge, skills and values intrinsic to the culture of the composer, and also conveys emotions and feelings common to all cultures can therefore be said that music is an ideal instrument for the establishment of a dialogue exchange. Communicative action music has always been analyzed, although it has been the lack of cultural dialogue which has increased the consideration that music can facilitate the way for the acquisition of Interculturalism. This article shows how music promotes intercultural communication process, when considered as the main tool in culturally diverse educational settings. It shows how music helps build a sense of belonging and evaluate own and others' productions, making extrapolation to other activities of daily living. This article helps to show how one can consider the music as cultural shows each country, is a product inherently intercultural facilities/promotes intercultural dialogue, due to its heavy burden of values and that carries the image of time and society membership.

Key words: music, intercultural comunication, interculturality, music creation, communication by means of the music practice.

Bernabé Villodre, M. (2012). La comunicación intercultural a través de la música. Espiral. Cuadernos del Profesorado, 5(10), 87-97. Disponible en: http://www.cepcuevasolula.es/espiral.

Fecha de recepción: 07/02/2012

Fecha de aceptación: 21/05/2012
Enviar correspondencia a: maria.mar.bernabe@uv.es 


\section{1.- INTRODUCCIÓN}

La manifestación artística musical tiene la capacidad de transmitir un conjunto de conocimientos, habilidades y valores que son intrínsecos al artista que la ha producido y, al mismo tiempo, transmite emociones y sentimientos que pueden considerarse comunes a todas las culturas que comparten un territorio. Sin embargo, puede considerarse mucho más que una manifestación artística (Bernabé, 2011) ya que, debido a las características del denominado lenguaje musical, es un medio más de comunicación y, por extensión, podría decirse que de comunicación intercultural. Esa posibilidad de comunicarse interculturalmente a través de la práctica y el estudio musical es uno de los objetivos que pretenden mostrarse en este artículo; puesto que se parte de la consideración de que determinadas prácticas musicales en el aula pueden convertir a la música en una base para el establecimiento del diálogo intercultural.

Se parte de comprender el acto de comunicarse como la espera de una respuesta por parte del receptor del mensaje y para conseguir esa comunicación deben conocerse y respetarse las características de éste, para que la labor de decodificación se lleve a cabo en las mejores condiciones posibles. De manera que, partiendo del terreno educativo el lenguaje del emisor (docente) debe adaptarse al receptor (discente) quien estará condicionado por sus necesidades, por su situación sociofamiliar, etc. Así pues, todo docente debe estar preparado para hacer frente a las preguntas y necesidades de sus alumnos, de forma que el proceso comunicativo que entre ellos se establezca le ayude en la construcción de su propio aprendizaje. Sin embargo, la formación musical en las diferentes etapas educativas no debe quedar reducida a un simple proceso de transmisión y adquisición de conocimientos por parte de los agentes implicados en el proceso educativo; sino que debe valorarse la vertiente creativa de la música y todas las posibilidades que ésta ofrece desde el punto de vista comunicativo y, principalmente, comunicativo entre las diversas culturas presentes en el aula.

El proceso de creación musical da lugar a situaciones comunicativas que no quedan limitadas a las palabras, ya que favorece la comunicación de emociones y el acercamiento entre el alumnado basado en una primera toma de contacto con experiencias musicales que pueden ser desconocidas para todo el alumnado. Esas situaciones comunicativas estarán basadas en un intercambio de "productos" propios, de resultados de la experimentación musical, y caracterizadas por la escucha y el respeto que supone la misma. Y, serán precisamente esas características del proceso interpretativo musical las que se han considerado que convierten a la música en una herramienta más para conseguir una comunicación intercultural y, a la larga, las que garantizarán la consecución de la preciada interculturalidad en el aula musical de cualquier etapa educativa.

La UNESCO (2006, p. 10) propone estudiar las obras de arte y "la participación en actividades artísticas", ya que a través del arte se puede conocer en profundidad la propia cultura para tomar conciencia de los elementos prestados (y adoptados finalmente) de otras culturas que convivieron o compartieron territorio en siglos pasados. Los préstamos siempre han sido característicos a lo largo de toda la Historia de la Música Occidental (y Oriental) y no hacen más que demostrar los intercambios culturales constantes a lo largo de los siglos. Esos elementos prestados que eran considerados de gran valor y riqueza para la pieza del compositor, en muchas ocasiones llegaron a considerarse como propios de otro lugar conforme pasaron los siglos, tal y como puede comprobarse con la música flamenca que es considerada como "tipical spanish" y, realmente, tiene un origen oriental sobre el que se ha discutido mucho.

Diversas propuestas de actividades musicales centradas en la música actual de intérpretes como Manu Chao o Ismael Serrano (Sanfeliu y Caireta, 2005), cuya temática se centra en temas sociales y que muestran influencias musicales de diferentes culturas es una forma de acercar otras músicas al alumnado de escolarización obligatoria. Segura y Ortells (2003) proponen la inclusión de música judía y musulmana con la novedad de incluir la colaboración familiar en cuanto a la selección musical, con la importancia que esto supone para que el proceso educativo sea completo al hacer partícipes a todos los implicados en el proceso de enseñanza/aprendizaje. Son muchas las propuestas educativas musicales de tipo multicultural que aparecen etiquetadas como interculturales, pero que al basarse en la simple interpretación de músicas de diferente procedencia (por ejemplo, Gallego y 
Gallego, 2003) no contribuyen más que (y que no es poco, ciertamente) a dar a conocer otras culturas para evitar el racismo y la intolerancia fruto del desconocimiento. Un comentario independiente merece propuestas como las de Polo y Nani (s.f.) y las de Bernabé (2011) que incluyen objetivos de tipo cultural, valores y actitudes interculturales que deben trabajarse para que el acto educativo intercultural tenga lugar en el aula de música.

Con este tipo de actividades de música se fomenta la adquisición de la competencia cultural y artística que, de acuerdo con Bellido (2010, p. 5), se refiere al "dominio de aquellas capacidades que permiten expresarse a través de diversos códigos artísticos, así como comprender y valorar críticamente las diferentes manifestaciones culturales y artísticas"; al tiempo que se pretende conseguir un ambiente de contacto o, más bien, de conocimiento entre las diferentes culturas, que desemboque en la adquisición de una competencia intercultural. Es decir que el proceso creativo musical lleva a la apreciación de la diversidad cultural y al respeto de la libertad de expresión; de ahí la importancia de la música como medio de comunicación intercultural. No obstante, se debe realizar una pequeña concreción, ya que actividades como las comentadas se acercan más a los objetivos de la denominada Educación Multicultural que a los de la Educación Intercultural, comprendiéndose que la primera trata de evitar posturas racistas y xenófobas mediante el conocimiento, pero sin intercambio ni reconstrucción común, mientras que la segunda sí pretende la construcción de una cultura común que una al alumnado presente en el aula, caracterizada por diversos elementos de todas ellas. En este artículo se pretende mostrar cómo la Música se puede convertir en un instrumento de comunicación intercultural, a lo que contribuye el análisis de las propuestas comentadas y las directrices que se incluyen.

De acuerdo con Vilà (2007) una comunicación intercultural eficaz no supone conocer otras culturas sino repensar la propia, alejarnos de estereotipos, promover las relaciones... Debe señalarse que la práctica musical puede favorecer el desarrollo de procesos comunicativos interculturales en otros contextos diferentes al formal: por ejemplo, la red de internet ofrece experiencias interculturales musicales de artistas que pretenden conseguir con sus actuaciones un acercamiento entre culturas; además son muchos los ayuntamientos que proponen experiencias de acercamiento intercultural basadas en meras manifestaciones de danza y música, en las que dichos espectáculos se convierten en una forma de mostrar/conocer otras realidades culturales para respetarlas; pero, al basarse únicamente en la muestra y no en el intercambio quedan limitadas a prácticas multiculturales que no ayudan en la construcción de una nueva cultura compartida que suponga la desaparición de los diferentes problemas derivados del contacto entre culturas. Esta misma opinión es defendida por Padrós y Tellado (2009), que critican el escaso cambio curricular que implican, el desarrollo y continuidad de estereotipos, cómo estas prácticas obvian cuestiones centradas en la discriminación y la desigualdad, y no establecen vínculos con el éxito académico del alumno, sino sólo en cuanto a la adquisición de valores.

En este artículo se pretende mostrar cómo la comunicación intercultural puede conseguirse con éxito a través de la música. Se parte de la consideración de que el proceso educativo musical, que desemboca en la interpretación musical y en la adquisición de unos contenidos específicos caracterizados por la diversidad cultural hecha propia por cada sociedad, pueden contribuir al desarrollo de un proceso comunicativo en igualdad de condiciones para todos sus participantes, además de que gracias a esa comunicación intercultural que se puede desarrollar en el aula de música se podrá conseguir la denominada interculturalidad. Interculturalidad entendida como meta caracterizada por una situación de intercambio cultural en igualdad, como construcción de una cultura compartida a cuyo desarrollo todos contribuyan, como situación de respeto, conocimiento, intercambio y reconstrucción. Para mostrar cómo es posible conseguir todo esto a través de la música, se ahondará más específicamente en el proceso artístico entendido como proceso comunicativo y se intentará mostrar cómo el aula de educación musical puede considerarse un espacio más para el trabajo de la comunicación entre culturas, y no sólo para la adquisición de la competencia artística porque Europa está demandando resultados como la comprensión intercultural, la participación cultural o el trabajo en equipo (Agencia Ejecutiva en el Ámbito Educativo, Audiovisual y Cultural, 2009). 


\section{2.- EL PROCESO COMUNICATIVO INTERCULTURAL}

Antes de reflexionar acerca de la música como medio de comunicación intercultural, debemos comentar muy brevemente las características principales del proceso comunicativo intercultural, para mostrar cómo las características de éste pueden encontrar una adecuada correspondencia en aquellas propias de la música; de manera que podremos llegar a concluir que la comunicación intercultural puede tener lugar a través de la música.

De acuerdo con Martín (2003) el acto comunicativo no consiste únicamente en un intercambio de información, sino que implica una negociación de las relaciones con el otro, la transmisión de una imagen y la percepción del interlocutor. A todas estas características debería añadirse la importante consideración de De la Torre (2001), para quien además debería contarse con un código compartido si se quiere que el proceso comunicativo sea intercultural. Bien, pero, realicemos una primera reflexión, ¿acaso no existe un lenguaje no verbal con el que se puede conseguir cierto grado de comunicación con el receptor? ¿Acaso no han surgido numerosos artículos centrados en la inteligencia emocional o en los diferentes tipos de inteligencia que puede desarrollar el ser humano? Desde este punto de partida, con el lenguaje se encontraría una situación similar: lenguaje verbal, gestual, de la mirada...

Vargas (2008) llega a una interesante conclusión sobre el uso del lenguaje verbal como medio de comunicación: por un lado es un vehículo que permite al ser humano navegar por sus pensamientos, sentimientos y conocimientos, pero también puede llevarle a naufragar. La música puede considerarse un lenguaje no verbal (con su propio código) que expresa emociones, estados de ánimo, sentimientos respecto a determinadas situaciones, elementos o personas. Y, aquí, es necesario apoyarse en Touriñán (2005) que defiende que la comunicación intercultural se puede identificar con procesos de interacción verbales y no verbales, entre miembros que pertenecen a grupos culturales diferentes.

De manera que, podemos definir la comunicación intercultural como "un intercambio entre personas procedentes de culturas diversas que consiguen comunicarse de una forma razonable" (Toledo, 1999, p. 1). La comunicación intercultural sólo podrá producirse cuando los grupos que participen del acto comunicativo asuman los significados del otro, es decir, cuando comprendan y entiendan qué significados tienen determinadas acciones para el otro. Así, el hecho de hacer partícipes a los demás de nuestros conocimientos y pensamientos podría considerarse la definición más próxima a los objetivos del diálogo intercultural que es la base primordial para la Educación Intercultural, que supone apostar por la incorporación de la diversidad cultural el proyecto educativo (FETE-UGT, 2009). Principalmente, mediante el diálogo intercultural se pretende alcanzar un grado de comunicación, entendida como intercambio, que permita la construcción de una cultura común en la que tengan acogida los mejores elementos de cada una de las presentes en una situación de igualdad. Y, será ese proceso comunicativo intercultural el que posibilite una situación de interculturalidad.

Cuando se conoce la cultura del receptor se consigue una mayor eficacia en el proceso comunicativo. Dicho proceso comunicativo entre culturas sólo puede tener lugar cuando los grupos participantes asuman los significados "del otro", cuando comprendan y entiendan los significados de determinadas acciones para "el otro". Esto implicará una reflexión propia de la cultura de pertenencia que permitirá comprender la cultura de llegada. A esa comprensión de la cultura propia contribuirá el modelo educativo vigente, fruto de la conciencia de la diversidad cultural que durante los últimos años ha llevado a eliminar la consideración de escuela homogénea (Colectivo Yedra, 2009). Es decir, la comunicación intercultural obliga a cambiar a nivel educativo, a trabajar diferentes puntos de vista, a interpretar la realidad de una forma menos rígida, a ser capaces de repensar la propia cultura y de superar el choque cultural. La música puede contribuir a repensar la propia cultura, sobre todo, al tomar consciencia de cómo se han aceptado como propios gran cantidad de elementos con un origen oriental o de otras zonas occidentales. Esa es la idea, precisamente: por ejemplo, la música española es fruto de influencias árabes, hebreas, italianas, francesas..., pero esos elementos que puedan formar parte de ella se han "asimilado" como propios, puesto que ya en su momento se produjo un proceso de "repensar" la música.

Cuanto más conocemos otras culturas, más se reflexiona sobre la propia, consiguiendo resaltar las semejanzas que las unen más que las diferencias entre ellas; de modo que si se quiere establecer 
una comunicación intercultural en igualdad, se debe prestar atención a los elementos contextuales que permitan que ambas partes se sientan en razonable igualdad de condiciones. Entonces, desarrollar una comunicación intercultural eficaz supondrá ser capaces de repensar la propia cultura, de reconocer y superar el choque cultural, promoviéndose relaciones en la vida cotidiana y el entendimiento común (García, 2009). Así, los objetivos de la comunicación intercultural, según Rodrigo (1999), serían: establecer los fundamentos del intercambio intercultural, eliminar los estereotipos negativos que cada cultura produce de las otras culturas, iniciar la negociación intercultural, y relativizar la propia cultura para comprender y aceptar valores alternativos. Básicamente, puede afirmarse que la comunicación intercultural será el medio de garantizar una convivencia pacífica. La convivencia implica responsabilidad compartida y de participación, y una educación en valores (Colectivo Yedra, 2009), y añadamos en los valores de la diferencia.

Todo proceso comunicativo intercultural quedará satisfecho cuando se llegue a un grado de comprensión aceptable para los interlocutores, puesto que la comunicación implica transferencia de información y el uso compartido de ésta. Así pues, sólo será posible si entre emisor y receptor tiene lugar cierto intercambio. Podemos decir, entonces, que la comunicación es la esencia de la profesión docente porque el proceso de enseñanza/aprendizaje es bidireccional, implica intercambio, retroalimentación, revisión,...; y por todo esto, el proceso de enseñanza musical puede considerarse una forma más de conseguir una comunicación entre las diferentes culturas presentes en el aula, un medio de consecución de la tan preciada interculturalidad, entendida como fenómeno de interacción entre culturas y relacionada con el respeto, la simetría, la convivencia (Cámara, 2010).

Obviamente para que un proceso comunicativo se desarrolle con las mayores garantías de éxito se precisan factores y elementos diversos, entre los cuales la música debería tener un lugar destacada puesto que contribuye al establecimiento de ese proceso comunicativo no verbal que permitirá al docente la comprensión del estado anímico y emocional del discente, punto de partida para la determinación metodológica del trabajo en el aula.

\section{3.- MÚSICA COMO MEDIO DE COMUNICACIÓN}

Con el devenir de los años la música (tanto su perfil teórico como su perfil interpretativo) ha gozado de diversas consideraciones, ya fuese una gran importancia como manifestación del afecto a la divinidad, ya fuese como un elemento intrínseco a las manifestaciones fúnebres y cotidianas, o ya fuese como una muestra del mayor nivel cultural de una determinada clase social. En estas páginas nos interesa la consideración de la música como manifestación de la cultura de un pueblo; con una interesante apreciación: la música como fruto de diferentes manifestaciones que terminan coincidiendo, aunándose en una manifestación común y compartida.

Correa (2006) considera la música como un medio de comunicación similar a cualquier otro, aunque transmita sensaciones. La comunicación emocional es también muy importante cuando dos personas entran en contacto. Pero esa reflexión acerca del poder comunicativo de la música más allá de la limitación a la transmisión emocional ha sido objeto de análisis durante siglos. Básicamente, se han descrito dos líneas en la percepción del texto musical: una que considera que la música evoca sentimientos, emociones y acontecimientos; y, otra que considera que la música es un arte con un significado en sí mismo, no refiriéndose a otras realidades diferentes a las de su propio campo, entre las que entraría la apreciación de sus diferentes elementos propios resultado de diferentes influencias de diversas procedencias culturales. Se parta de una premisa o de otra, resulta lícito considerar que la música crea actitudes positivas ante el proceso de aprendizaje intercultural porque su práctica y aprendizaje parten del conocimiento de la procedencia de los elementos que la caracterizan, de la interiorización de una serie de normas de intervención caracterizadas por el respeto a la aportación e intervención del otro, convirtiéndose además en una actividad participativa, creativa y entretenida.

Actualmente, se está considerando que la música tiene una cualidad más que debe potenciarse: la de posibilitar la adquisición de la interculturalidad, comprendida como un estado ideal de convivencia en sociedades pluriculturales cuyas relaciones interpersonales están basadas en el respeto gracias al conocimiento mutuo. En esa misma línea la Hoja de Ruta para la Educación Artística (UNESCO, 
2006) establece que cada cultura desarrolla unos medios mediante los cuales comparte y se comunica para comprender el mundo y cuenta con elementos comunes a todas ellas. De manera que todo proceso artístico puede considerarse un medio de comunicación emocional, cognitivo, del compositor y del entorno cultural de éste; así que la música puede considerarse un instrumento, una herramienta o un medio de comunicarse con otras culturas, si partimos de la consideración que el conocimiento que aporta y las interrelaciones que tienen lugar en su proceso de interpretación llevarán a la consecución de la interculturalidad. La música, entonces, se convierte en "herramienta para cambiar la realidad, no sólo de los artistas, sino también de aquellas personas receptivas del arte" (Rebernak y Muhammad, 2009, p. 269).

No puede considerarse que el lenguaje de la música se mueve sólo en el terreno de lo abstracto, puesto que muestra una gramática real desde que el discurso del compositor surge de su pensamiento hasta que llega al público debido a las "diversas fases a través de un recorrido complejo, en el que se desencadenan procesos comunicativos propios de este lenguaje, como el análisis de la obra, la interpretación (...) la percepción y la comprensión” (Palomares, 2004, p. 15). La música puede no ser un lenguaje musical en sentido estricto pero sí en sentido práctico (Cruz Roja Española, 2009), puesto que está sujeto a la interpretación personal, al contexto social, a las emociones de los participantes en el acto comunicativo...

El arte es un generador de la creatividad natural del educando y estimula los elementos imprescindibles para garantizar el respeto de la alteridad como son los valores de respeto a la producción del otro, el silencio ante otras producciones musicales... También comparte esta argumentación Bellido (2010, p. 6), que presenta la música como un proceso creativo que aportará al alumno "habilidades perceptivas y comunicativas, imaginación y creatividad para expresarse (...), habilidades para (...) apreciar iniciativas y contribuciones ajenas, identificar los vínculos entre sociedad y manifestaciones culturales”. De modo que la creación e interpretación musical aportarán al discente las herramientas adecuadas para poder comunicar su propia cultura y comunicarse con "el otro" gracias al conocimiento de esa otra cultura que le aporta la música.

Muchos los teóricos de la Historia del Arte (Gombrich, 1997) han considerado al arte como la herramienta educativa más adecuada en este mundo altamente mediatizado, convirtiéndose en el instrumento principal que permitirá al ser humano desarrollarse como individuo. Así, la música como manifestación artística, al no reducir a palabras la expresión de sentimientos y estados emocionales, contribuye a garantizar el entendimiento grupal, la autocomprensión interior, olvidándose el hecho de que no se comparta la misma lengua. El docente conseguirá cambiar a los receptores musicales (alumnado) mediante la observación, el análisis y la valoración de diferentes realidades sonoras; pero, ¿cómo ayuda la música a conseguir ese cambio? La música como práctica artística ayudará en la apertura mental hacia "el otro", en la valoración y exploración de las emociones propias y ajenas, en la "revisión” cultural propia. Así, la práctica musical se convierte en un vehículo garante de la comunicatividad emocional de los alumnos y, al mismo tiempo, en vehículo de expresión-conocimiento de diferentes culturas.

Sin embargo, para conseguir que la música se convierta en ese vehículo de expresión de diferentes culturas debe partirse de cuatro supuestos, de acuerdo con Schafer (1988): primero, se deben descubrir las potencialidades creativas del alumnado; segundo, se debe reconocer y valorar el paisaje sonoro; tercero, se debe buscar un espacio artístico común; y cuarto, se deben considerar importantes todos los sonidos producidos. Estos dos últimos supuestos serían los más relevantes para que la comunicación intercultural pudiese tener lugar. Todo esto podría encontrarse en el aula educativa, entendida como "lugar propio para la conservación, transmisión y generación de valores culturales" (Frega, 2004, p. 13). No obstante, debe señalarse que el aula musical no sólo es un lugar apropiado para la transmisión de valores culturales sino que al caracterizarse por el trabajo cooperativo se está favoreciendo el afecto entre los participantes: cuanto más conocimiento y más interrelación, podrán desarrollarse más relaciones afectivas y de respeto mutuo en el aula. Durante la actividad musical el alumnado se interrelaciona, comparte y necesita comprender la producción del compañero, todo ello es imprescindible para la consecución de una obra musical a gusto de todos los participantes. 
La asignatura de música en el centro educativo se convierte en un instrumento de grandísima utilidad para afrontar el proceso de "cambio" en las miradas hacia "el otro" (Bernabé, 2011). En el aula de música se debe partir, entre otros, de un recurso tan importante como la improvisación que implica un aporte de vivencias que ayudan a conformar el conocimiento de la realidad y contribuyen a la integración social del educando. Además, ese proceso de integración social que tiene lugar en el aula musical se produce gracias a que la música atrae a todo el alumnado, de manera que será el mejor vehículo para el trabajo de la comunicación intercultural siempre que todos los agentes implicados (docentes, educandos y familias) cumplan con su parte; es decir, favorezcan entornos de intercambio y colaboren estrechamente en el proceso de enseñanza/aprendizaje.

La educación musical recibida en un contexto educativo obligatorio supone el descubrimiento de un nuevo medio de expresión y comunicación que le llevará a conocer y expresar sus capacidades (Conejo, 2012); además de que le permitirá cultivar su espíritu, su mente, dirigirse a otros seres humanos (Arguedas, 2004), conocer las del compañero y hacerle partícipe de las suyas, al tiempo que participa de las de éste.

\section{4.- CONCLUSIONES: LA MÚSICA COMO MEDIO DE COMUNICACIÓN INTERCULTURAL}

La música pone de manifiesto la dimensión comunicativa del sonido e implica una red discursiva. El docente debe tener en cuenta que el proceso de enseñanza de la música se puede dividir en una enseñanza teórica y en una práctica, pero tanto en una como en otra, las posibilidades de favorecer el proceso de comunicación intercultural son igualmente posibles. Desde este epígrafe final queremos mostrar cómo los docentes de todos los niveles educativos obligatorios pueden aprovechar las posibilidades de la música como favorecedora del proceso comunicativo intercultural. Aunque, queremos abrirlo a otros profesionales de la educación para que comprendan lo que les ofrece el recurso de la música en cuanto al proceso de adquisición de la interculturalidad que es el objetivo final de la comunicación entre culturas.

La presencia de la música en el currículo de las diversas etapas educativas obligatorias puede traducirse como el intento de crear un espacio de mutuo acercamiento (Bernabé, 2012), puesto que todos los colectivos tienen su presencia en este aula, todos los alumnos acuden a esta clase y participan de las mismas actividades, mientras que en otras clases son divididos y separados en niveles o para acudir a sesiones de refuerzo. Ante esta situación resulta lícito considerar que la clase de música se convierta en un espacio de comunicación interpersonal a través de la práctica musical; y debido a esto, puede interpretarse la música como una "herramienta" más útil que otras asignaturas para garantizar la comunicación intercultural entre el alumnado: en ese tiempo lectivo todos los alumnos conviven en igualdad de condiciones, comparten los entresijos de la práctica musical, dependen los unos de los otros para conseguir transmitir el mensaje musical, necesitan escuchar al compañero para intervenir, el conocimiento y reconocimiento de las características musicales les es imprescindible para garantizar una adecuada interpretación... El docente debe ser consciente de todas estas implicaciones de la práctica musical y promover la mayor cantidad posible de actividades prácticas interpretativas para que el alumnado se comunique y, por tanto, intercambie para llegar a un resultado interpretativo satisfactorio para todos y cada uno de los participantes, pertenezcan a la cultura que pertenezcan.

Así, el aula de música se convierte en el escenario más adecuado y útil para trabajar la interculturalidad. La razón de su consideración como principal punto de desarrollo de la comunicación intercultural estriba en que la música, como parte de la cultura de cada país, tiene su presencia en la educación formal y el currículo ha tratado de recoger las manifestaciones propias de cada zona del país, incluso aceptando las manifestaciones musicales propias de otras zonas del continente europeo y de zonas orientales. Todo esto debe agradecérsele a la existencia en el territorio de otras culturas no occidentales que, cada vez más, reclaman la consideración de su presencia de cara a la práctica educativa, basándose en su derecho a un proceso educativo de calidad y en igualdad de condiciones. Aunque, debemos señalar que la interpretación de canciones de diferentes culturas o de canciones de cantantes de la cultura propia es una actividad extensible a otras asignaturas como Lengua Extranjera (inglés, ale- 
mán, etc.) o Educación Física; en estas asignaturas la utilización de material musical de otras culturas puede contribuir no sólo al conocimiento de otras músicas por parte del alumnado, sino al conocimiento de otros valores que éstas puedan expresar. Por ejemplo, no sería lo mismo trabajar una canción inglesa de un grupo como Coldplay que una canción procedente de Sudáfrica que también habla inglés.

Debido a que la música encierra varias posibilidades interpretativas y cuenta con significados abiertos, ofrece un lenguaje accesible para todos los intérpretes que, normalmente, aprenderán al mismo tiempo a comunicarse con ella si se encuentran en Primaria y reforzarán esta capacidad si se encuentran en Secundaria. Cuando el alumnado es iniciado en el mundo de la teoría musical suelen presentar el mismo nivel (salvo excepciones de educandos que asistan a clases particulares de música) si no se trata de alumnos de incorporación tardía al sistema educativo español, hecho que permite considerar que este aprendizaje teórico se produce en las mismas condiciones para todos ellos. En este aprendizaje las "letras" son las notas, con denominación similar en casi todos los países, si que es cierto que algunos signos tienen diferentes nombres pero la misma representación gráfica, hecho que facilita su aprendizaje (en otras materias el lenguaje es totalmente diferente y más complicado de asimilar para aquellos educandos que tienen una lengua diferente a la del país de acogida). Son cuestiones como éstas las que deben llevar al docente a considerar la música como una herramienta imprescindible para la consecución de la interculturalidad en el aula de educación obligatoria, así como a promover su uso en el resto de asignaturas del currículo escolar.

La música despierta reacciones emocionales y cognitivas en las personas que la practican, influyendo positivamente en su proceso de aprendizaje. De igual modo, la música facilita la comprensión y asimilación del lenguaje que utiliza, ya sea la lengua propiamente dicha o el lenguaje musical en sí mismo. El docente debe tener en cuenta la aportación del proceso de enseñanza de la teoría e historia de la música para el desarrollo del proceso comunicativo intercultural en el aula de música; es decir, el estudio de las características estilísticas de la música a lo largo de los siglos no harán sino mostrar al alumno cómo diferentes características propias de diversas zonas del mundo fueron asimiladas como propias por otras tras sumar las características propias, y cómo esa fusión se desarrollaría de formas diferentes y volverían a verse nuevamente influidas por conquistas, alianzas políticas, etc. De este modo, el alumnado podrá comprobar cómo la interculturalidad es posible y la clase de música podrá convertirse en un espacio de comunicación intercultural garantizado por el refuerzo que supone la práctica musical.

Si el docente parte en sus clases de la práctica musical, el receptor musical puede considerarse algo más que un consumidor porque está implicado con el emisor para dotar de sentido al texto musical. El proceso de recepción en la comunicación musical es activo porque cada receptor interpreta y pone en funcionamiento nuevos procesos comunicativos, a su vez, y en esto residiría parte de la importancia de la música como instrumento de comunicación intercultural y, por extensión, de Educación Intercultural, que implica la adquisición de un compromiso educativo que permitirá llegar a construir una escuela sin exclusiones (Leiva, 2011). La gramática musical es real desde el momento en que el discurso surge del compositor y llega al público, no se mueve en el terreno de lo abstracto pese a la consideración de que su lenguaje no se ciñe a las palabras; y, esa "falta de palabras", de oralidad, es precisamente la que lleva a la música a convertirse en transmisora de mensajes de diferente tipo. La música es un discurso sonoro que comparte signos con otros lenguajes, de ahí su relevancia para la comunicación intercultural, y de ahí la importancia del trabajo de unos valores interculturales por parte de los docentes (Bernabé, 2011), tales como el respeto a la alteridad, el intercambio y la reconstrucción de una cultura común...

Las estructuras repetitivas y simples de las canciones populares facilitan la comprensión y asimilación del lenguaje musical, al tiempo que facilitan la comprensión de ese lenguaje musical y la comprensión de otras características musicales o la reinterpretación de las características musicales propias. El docente tiene que comprender la interpretación musical como el instrumento adecuado para facilitar la relación entre los educandos, la comunicación entre ellos y su aprecio mutuo; además, la interpretación musical favorece el intercambio cultural inconsciente que debe convertirse en el punto de partida para el citado intercambio entre culturas. No debe olvidarse que el aprendizaje de una lengua en el centro educativo no se limita a la gramática y la ortografía, sino que se aprenden características 
de ésta; y, el docente debe ser consciente de que en el aprendizaje musical sucede lo mismo, sólo que el ambiente en el que transcurre dicho proceso resulta tan cercano, tan ameno, al alumnado, que éste muestra una mayor predisposición.

Las materias artísticas son las que han recogido el testigo de la Educación Intercultural, de acuerdo con lo establecido en la legislación educativa vigente. En ellas se han incluido aspectos que contribuyen a la aceptación de la transformación social actual debidos a los contactos con los nuevos ciudadanos del territorio español, es decir, que la inclusión de contenidos teórico-prácticos como el estudio de las características musicales de otras culturas y la interpretación de sus obras principales contribuirán a la adquisición de la interculturalidad. A través de la interpretación de la música, el docente tendrá que conseguir el establecimiento de espacios para la autoexpresión, el entretenimiento compartido, el respeto a las prácticas diferentes, etc.; todo ello, para garantizar el respeto a la diversidad y su aceptación y apreciación. A esa apreciación contribuirá el conocimiento adquirido gracias al estudio más teórico de la música, es decir, gracias al estudio de la historia de la música de las diferentes zonas del mundo.

Los docentes tenemos que lograr la integración de las manifestaciones culturales en la escuela para desarrollar su proceso socializador, colaborador y de autonomía personal; además de que la interpretación de unas obras musicales con determinadas características estudiadas, permitirá al alumnado conocer las diferentes culturas que les rodean y reforzar y repensar la suya propia. Es decir, la música debe entenderse como una muestra cultural más de cada país, de cada comunidad lingüística (Martínez, 2006), así como un producto "intrínsecamente intercultural” y cargado de valores (en el caso de canciones con letra). Por todo esto, los docentes de música de las diferentes etapas educativas obligatorias deben considerarla uno de los vehículos más adecuados para el trabajo de la interculturalidad porque la música lleva consigo la imagen del tiempo y de la sociedad de la que parte, convirtiéndose de este modo en la herramienta idónea para la pedagogía intercultural y para la comunicación intercultural que ésta implica. Pero, principalmente, los docentes debemos mostrar que la diversidad cultural presente en el aula es un colectivo que no debe tratarse de forma diferenciada (Verde, 2010) o separada.

En síntesis, la música ayuda a construir un sentido de pertenencia y a valorar las producciones propias y ajenas, facilita la extrapolación a otras actividades de la vida cotidiana y el trabajo de la transversalidad. La música es, al fin y al cabo, una muestra cultural más de cada país y un producto intrínsecamente intercultural con una gran carga de valores, llevando consigo la imagen del tiempo y de la sociedad de pertenencia; ya que es capaz de expresar la realidad material y humana de cada sociedad (Campos, 2004), y puede considerarse testigo excepcional de la cultura contemporánea (Porta, 2003). Pero, es además, como manifestación artística que es, se convierte en uno de los instrumentos más poderosos de la naturaleza humana (Pérez, 2009) para el cambio. Y, por todo esto, se puede afirmar que la comunicación entre culturas a través de la música es una realidad en el aula educativa.

\section{5.- REFERENCIAS BIBLIOGRÁFICAS}

Agencia Ejecutiva en el Ámbito Educativo, Audiovisual y Cultural (2009). Educación artística y cultural en el contexto escolar en Europa. Madrid: Secretaría General Técnica.

Arguedas, C. (2004). La expresión musical y el currículo escolar. Educación. Revista de la Universidad de Costa Rica, 28(1), 111-122.

Bellido, J.A. (2010, enero). Competencia Cultural y Artística. El papel de la creatividad en la búsqueda de itinerarios posibles para el tránsito desde el lujo a la necesidad. Trabajo presentado en el I Congreso de Inspección de Andalucía: Competencias básicas y modelos de intervención en el aula, Mijas Costa, Andalucía.

Bernabé, M. (2011). La Educación Intercultural en el aula de Música. Unidades didácticas interculturales para Educación Primaria. Saarbrücken: Editorial Académica Española.

Bernabé, M. (2012). Cómo organizar el proceso de enseñanza musical de forma intercultural: propuestas para trabajar interculturalmente en el área de Primaria. DEDiCA. Revista de Educación y Humanidades, 2, 235-248. 
Cámara, E. (2010). El papel de la etnomusicología en el análisis de la música como mediadora intercultural. Historia Actual Online, 23, 73-84.

Campos, J.L. (2004). Procesos interculturales en la comunicación digital y las transformaciones de la industria musical. Sphera Pública, 4, 101-118.

Colectivo Yedra (2009). Convivencia escolar. Madrid: Cyan, Proyectos y Producciones Editoriales S.A.

Conejo, P.A. (2012). El valor formativo de la música para la educación en valores. DEDiCA. Revista de Educación y Humanidades, 2, 263-278.

Correa, J.P. (2006). Reflexiones sobre la cognición en la creatividad musical. Anuario, 29, 402-426.

Cruz Roja Española (2009). Cuaderno de actividades. Una propuesta para trabajar la Interculturalidad. Madrid: Cruz Roja Española.

De la Torre, S. (2001). La comunicación didáctica: modelos y pautas para la acción. En F. Sepúlveda y N. Rajadell (Coord.), Didáctica general para psicopedagogos (pp. 103-151). Madrid: UNED.

FETE-UGT (2009). La Gestión de Centros Interculturales. Guía del Profesorado. Madrid: Cyan, Proyectos y Producciones Editoriales S.A.

Frega, A.L. (2004). Los lenguajes artísticos. Su importancia como ámbitos para la estimulación de la creatividad en la educación escolar. Foro Virtual. Vicaría Episcopal de Educación.

Gallego, C.I., y Gallego, M. M. (2003). Interculturalidad en educación infantil y primaria con la música. Filomúsica. Revista mensual de publicación en internet, 37. Disponible en: http://www.filomusica.com/filo37/interculturalidad.html. Consulta [2010, 10 de marzo].

García, A. (Dir.) (2009). El diálogo intercultural. Murcia: Universidad de Murcia.

Gombrich, E.H. (1997). La historia del arte. Madrid: Editorial Debate.

Leiva, J.J. (2011). La educación intercultural: un compromiso educativo para construir una escuela sin exclusiones. Revista Iberoamericana de Educación, 56 (1), 1-14.

Martín, L. (2003). Dimensiones principales de la comunicación intercultural. Educación y futuro: revista de investigación aplicada y experiencias educativas, 8, 81-90.

Martínez, M. (2006, mayo). Navegar entre canciones. Trabajo presentado en el III Encuentro Práctico de Profesores de ELE, Würzburg, Alemania.

Padrós, M., y Tellado, I. (2009). Cruce de culturas en la escuela. Revista Electrónica Teoría de la Educación. Educación y Cultura en la Sociedad de la Información, 10 (3), 159-179.

Palomares, J. (2004). Comunicar la música. Comunicar. Revista Científica de Comunicación y Educación, 23, 13-16.

Pérez, M.A. (2009). Una pedagogía dialógica desde la educación artística-musical. El Artista, 6, 60-72.

Polo, C., y Nani, A. (s.f.). Música de fusión. Disponible en: http://www.todoele.net/actividades_mat/CarmenPolo_Papelesmojados.pdf. Consulta [2012, 3 de mayo].

Porta, A. (2003, octubre). Nuevos retos para la comunicación musical. Trabajo presentado en el Congreso Iberoamericano de Comunicación y Educación. Luces en el Laberinto Audiovisual, Huelva, Andalucía.

Rebernak, J. y Muhammad, I. (2009). Interacciones artísticas y competencias interculturales en el Mediterráneo. Quaderns de la Mediterrània, 12, 265-270.

Rodrigo, M. (1999). La comunicación intercultural. Barcelona: Anthropos Editorial.

Sanfeliu, A. y Caireta, M. (2005). La música como instrumento de educación para la paz. Bellaterra: Universidad Autónoma de Barcelona.

Schaffer, R. M. (1988). Cuando las palabras cantan. Buenos Aires: Ricordi.

Segura, M. T. y Ortells, I. (2003). La Educación Musical en el contexto multicultural educativo de Melilla. Ejemplificaciones de programaciones. Granada: Universidad de Granada.

Toledo, C. J. (1999). Acerca de la necesidad de una competencia comunicativa intercultural. Tesina de Maestría, Universidad de La Habana, Ciudad de La Habana.

Touriñán, J. M. (2005). Educación en valores, educación intercultural y formación para la convivencia pacífica. Revista galega do ensino, 13/47, 1041-1102.

UNESCO (2006, marzo). Hoja de Ruta para la Educación Artística. Trabajo presentado en la Conferencia Mundial sobre la Educación Artística: construir capacidades creativas para el siglo XXI, Lisboa, marzo. 
Vargas, C. (2008). La voz, el canto y el arte de comunicar. Filomúsica. Revista mensual de publicación en internet, 88. Disponible en: http://www.filomusica.com/cantar.html. Consulta [2010, 24 de marzo].

Verde, I. (2010). Implicaciones educativas del contacto entre culturas. Teoría de la Educación. Educación y Cultura en la Sociedad de la Información, 11(3), 302-305.

Vilà Baños, R. (2007). Comunicación intercultural. Madrid: Narcea.

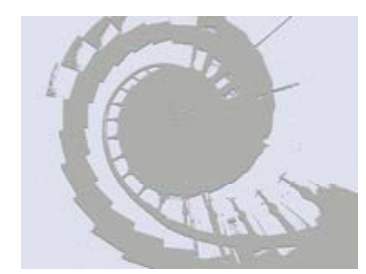

